\title{
7.1. ANEXOI
}

\section{CRITÉrios diagnósticos de doEnÇA DE PARKINSON}

UK PARKINSON'S DISEASE SOCIETY BRAIN BANK

Hughes A, Daniel S, Blankson S, Lees AJ.

A clinicopathologic study of 100 cases of Parkinson disease. Arch Neurol 1993;50:181-4.

(tradução do autor) 


\section{Fase 1 - Diagnóstico de Parkinsonismo}

1. Bradicinesia

2. Pelo menos um dos seguintes: (a) rigidez, (b) tremor de repouso ou instabilidade postural (não relacionada a disfunção visual, vestibular, cerebelar, ou proprioceptiva)

\section{Fase 2 - Critérios de exclusão para Doença de Parkinson}

1. História de doença cerebrovascular com progressão em etapas dos sinais parkinsonianos

2. História de trauma de crânio repetido

3. História de encefalite

4. Crises oculogiras

5. Tratamento com neurolépticos no início dos sintomas

6. Mais de um familiar afetado

7. Remissão mantida

8. Sinais estritamente unilaterais após 3 anos do início

9. Paralisia da mirada supranuclear

10. Sinais cerebelares

11. Disfunção autonômica precoce e intensa

12. Demência com apraxia precoce e intensa

13. Resposta plantar em extensão

14. Tumor cerebral ou hidrocefalia à tomografia computadorizada de crânio

15. Resposta negativa à levodopa (mais de $1 \mathrm{~g}$ por mais de um mês)

16. Exposição ao MPTP

Fase 3 - Critérios prospectivos que corroboram para o diagnóstico de Doença de Parkinson (pelo menos 3 são necessários para o diagnóstico definitivo)

1. Início unilateral

2. Tremor de repouso

3. Transtorno progressivo

4. Parkinsonismo persistentemente assimétrico

5. Resposta acentuada à levodopa / apomorfina

6. Intensas discinesias induzidas por levodopa

7.Resposta à levodopa por mais de 5 anos

8. Duração da doença por 10 anos ou mais 